\title{
EFEITOS DO ALUMÍNIO EM PIMENTEIRAS DO REINO (Piper nigrum, L.)CULTIVADAS EM SOLUÇÃO NUTRITIVA ${ }^{1}$
}

\author{
C.A.C.VELOSO²; T. MURAOKA ${ }^{3}$; E. MALAVOLTA ${ }^{3}$; J.G. de CARVALHO 4 \\ ${ }^{2}$ CPATU/EMBRAPA, C.P. 48, CEP: 66095-100, Belém, PA. \\ ${ }^{3}$ Centro de Energia Nuclear na Agricultura-CENAIUSP, C.P. 96, CEP: 13400-970, Ptracicaba, SP. \\ ¿Depto. de Ciência do Solo, ESALIAAVAS, C.P. 37, CEP: 37200-000. Lavras, MG.
}

\begin{abstract}
RESUMO: A pimenteira do reino (Piper nigrum, L.) vem sendo cultivada, em sua maior parte, em áreas com solos de baixa fertilidade natural, caracterizadas por baixa saturação por bases, alta saturaçăo de alumínio e acidez elevada. Visando estudar os efeitos do alumínio sobre a cultura foi conduzido um experimento com a cultivar Guajarina em solução nutritiva. As doses de alumínio estudadas foram: $0 ; 5 ; 10 ; 15 ; 20$ e $40 \mathrm{mg} / \mathrm{L}$. O sintoma inicial de toridez de alumínio foi caracterizado por um retardamento no crescimento radicular, com aumento no diâmetro das raizes. Observou-se efeito positivo do alumínio na produç̄o de matéria seca com adiçāo de até $15 \mathrm{mg} / \mathrm{L}$ na solução, o que correspondeu a major absorção de $\mathrm{P}, \mathrm{K}, \mathrm{Ca}, \mathrm{Mg}, \mathrm{Mn}$, Fe e Al. Concluiu-se que a pimenteira é tolerante à presença de concentraçoes de Al inferiores a $20 \mathrm{mg} / \mathrm{L}$ no substrato. Doses superiores provocam distúrbios nutricionais com reduçăo no crescimento da planta.

Descritores: Piper nigrum, toxidez de aluminio, absorção, nutrição
\end{abstract}

\section{EFFECT OF ALUMINUM ON BLACK PEPPER (Piper nigrum, L.) GROWN IN NUTRIENT SOLUTION}

\begin{abstract}
Black pepper (Piper nigrum, $L$.) is usually grown in soils of low natural fertility and high aluminum saturation. An experiment using young plants of the Guajarina cultivar grown in nutrient solution was carried out in order to verify the effects of aluminum on the growth and chemical composition and determine the concentration in the substrate which causes toxicity symptoms. Aluminum was added to the nutrient solution at the rates of $0,5,10,15,20$ and $40 \mathrm{mg} / \mathrm{L}$. The initial symptom of Al toxicity was a slower development of the roots, which were thicker than those of the control. Dry weight increased when aluminum supply increased from 0 to $15 \mathrm{ppm} A \mathrm{~A}$; correspondingly there was a higher uptake of $P$, $\mathrm{K}, \mathrm{Ca}, \mathrm{Mg}, \mathrm{Mn}$, Fe and $\mathrm{Al}$. It appears that black pepper is tolerant to Al concentrations as high as $20 \mathrm{mg} / \mathrm{L}$. Higher rates cause nutritional disturbances and reduction in growth.
\end{abstract}

Key Words: black pepper, aluminum toxicity, absorption, nut rition

\section{INTRODUÇÃO}

A pimenta do reino (Piper nigrum, L.) é uma espécie perene, arbustiva e trepadeira, originária de regiões tropicais da Índia. Seus frutos possuem alto valor comercial na forma de pimenta preta, pimenta branca e pimenta verde em conserva. Essa especiaria é empregada como condimento na alimentação, nas indústrias de carne e perfumaria (MAISTRE, 1969).

As principais áreas de produção de pimenta do reino no Brasil estão localizadas em regiões caracterizadas por solos ácidos, baixa saturação por bases e frequentemente, possuem alumínio trocável e manganês em quantidades suficientemente altas para limitar o desenvolvimento normal das plantas (FALESI, 1972).
O efeito nocivo de aluminio em plantas tem sido extensivamente pesquisado por muitos cientistas como FOY et al. (1978), PAVAN \& BINGHAM (1982), CAMBRAIA (1989), FURLANI (1989) e FOY (1992). Geralmente o efeito tóxico do Al é notado $\mathrm{em}$ raizes de plantas antes que qualquer sintoma possa ser evidente na parte aérea. Os sintomas de toxidez são também associados com deficiência de fósforo e com reduzida absorção e translocação de cálcio (FOY, 1974).

O excesso de alumínio inibe a formação normal de raizes, tornando-as engrossadas, inchadas, com coloração marrom, menos ramificadas, quebradiças e ocasionalmente com manchas necróticas (FOY, 1992).

O limitado crescimento das raizes restringe a absorção de nutrientes e água, o que pode afetar

\footnotetext{
${ }^{1}$ Parte do trabalho de tese do primeiro autor, apresentado à ESALQ/USP
}

Sci. agric., Piracicaba, 52 (2): 368 -375, mai./ago. 1995 
consideravelmente o rendimento das culturas, em solos com baixa fertilidade (FOY, 1992).

Na prática, o uso de corretivos da acidez diminue o efeito tóxico do alumínio. Há inúmeros resultados na literatura demonstrando que através da calagem dos solos ácidos elimina-se o $\mathrm{Al}$ trocável e aumenta-se a produção dos cultivos (PRATT, 1966; LOPES, 1984; MALAVOLTA \& KLIEMANN, 1985). Entretanto a recomendação dessa prática para a pimenteira do reino tem sido feita de forma empírica, sem ênfase ao aprofundamento do sistema radicular. Assim, são indicadas as aplicaçóes de pequenas doses na cova de plantio (ALBUQUERQUE et al., 1989).

Portanto, devido aos poucos dados de pesquisa disponíveis sobre o efeito nocivo de alumínio em pimenteiras, foi conduzido um experimento em solução nutritiva com os objetivos de verificar os efeitos do aluminio no crescimento e na composição química da pimenteira do reino, bem como determinar as concentraçðes de alumínio que induzem sintomas de toxidez.

\section{MATERIAL E MEtTODOS}

$O$ presente estudo foi realizado em solução nutritiva em casa de vegetação do Centro de Energia Nuclear na Agricultura, da Universidade de São Paulo, em Piracicaba-SP, no período compreendido entre abril a novembro de 1992.

Foram utilizadas mudas de pimenteira do reino (Piper nigrum, $L$.) obtidas de estacas herbáceas com dois entre-nós e providas de uma folha no nó superior, do cultivar Guajarina, coletadas em uma área de plantio comercial no município de Mirassolândia-SP.

Após 120 dias do início do enraizamento, as mudas foram retiradas do substrato (solo), as raizes lavadas com jato de água de tomeira e em seguida imersas em água desmineralizada para completar a limpeza. Em seguida o material foi selecionado, procurando-se uniformizar ao máximo através da escolha de plantas que apresentassem parte aérea e sistema radicular nas mesmas condições de crescimento. As mudas foram então transferidas para vasos plástico de 2,5 litros de capacidade e fixadas na tampa pelo caule com espuma de plástico, usando-se uma planta por vaso.

Durante os primeiros 15 dias após o transplante, as plantas foram mantidas em solução nutritiva completa (TABELA 1), de acordo com a metodologia usada por WAARD (1969), diluida a 1/4 da concentração usual; nas duas semanas seguin- tes receberam solução diluida a $1 / 2 \mathrm{e} \mathrm{em} \mathrm{seguida}$ foram submetidas aos tratamentos.

Usaram-se vasos de 2,5 litros de capacidade onde as plantas foram cultivadas em solução de WAARD (1969) modificada em relação à concentração de fósforo, que foi reduzida para $1,5 \mathrm{mg} / \mathrm{l}$ para evitar a precipitação do alumínio.

Os tratamentos consistiram na aplicação de alumínio nas concentraçð̃es de $0 ; 5 ; 10 ; 15 ; 20$ e $25 \mathrm{mg} / \mathrm{l}$ adicionado como $\mathrm{AlCl}_{3} \cdot 6 \mathrm{H}_{2} \mathrm{O}$. Aos 135 dias após a adição dos tratamentos, foi aumentada a dose 25 para $40 \mathrm{mg} / \mathrm{l}$, para acelerar a manifestação de toxidez de alumínio.

As soluçres nutritivas foram renovadas a cada duas semanas e o seu volume completado com água destilada diariamente. $\mathrm{O}$ pH das soluções foi mantido em 4,0 $\pm 0,2$ com adiçб̃es de $\mathrm{HCl}$ ou $\mathrm{NaOH}$.

A composição química da solução nutritiva usada para caracterizar a toxidez de alumínio é apresentada na TABELA 1.

Nas soluções de diversas concentrações de aluminio procurou-se visualizar também aspectos da fitotoxicidade manifestada nas raizes das plantas.

$O$ delineamento experimental utilizado foi inteiramente casualizado, com seis tratamentos e quatro repetições. A unidade experimental foi constituída por uma planta.

As mudas de pimenteira do reino foram mantidas com os tratamentos por um período de 215 dias. Na colheita, dividiram-se as plantas em partes, a saber: folha para diagnóstico (primeira folha mais velha dos ramos laterais frutíferos, localizados nos 2/3 mais abaixo da copa) e o restante da planta que, por sua vez, foi dividido em folhas, caule e raizes. As amostras foram secas em estufa de circulação forçada de ar a $60-70^{\circ} \mathrm{C}$, por um período mínimo de 72 horas, quando foram pesadas e moidas em moinho do tipo Wiley com peneira de 20 malhas, para posterior análise dos teores de $\mathrm{P}, \mathrm{K}, \mathrm{Ca}, \mathrm{Mg}, \mathrm{Mn}, \mathrm{Fe}$ e Al.

Determinou-se o peso da matéria seca das folhas, caule e raizes, sendo medido também o comprimento das raizes.

Para as análises químicas, as amostras do material colhido foram digeridas em ácido nítrico e perclórico concentrados, segundo o método descrito por MALAVOLTA et al., (1989). Em seguida, os extratos foram utilizados para a determinação dos teores totais dos seguintes nutrientes: fósforo, por colorimetria de molibdato-vanadato; potássio, por fotometria de chama; cálcio, magnésio, ferro e manganês por espectrofotometria de absorção atômica. 
TABELA 1. Composição da solução nutritiva usada para o estudo de toxidez de alumínio, modificada a partir de WAARD (1969).

\begin{tabular}{cc}
\hline \hline Nutrientes & Concentração $(\mathrm{mg} / \mathrm{l})$ \\
\hline $\mathrm{NO}_{3}$ & 80,5 \\
$\mathrm{NH}_{4}$ & 10,5 \\
$\mathrm{P}$ & 1,5 \\
$\mathrm{~K}$ & 39,0 \\
$\mathrm{Ca}$ & 80,0 \\
$\mathrm{Mg}$ & 24,0 \\
$\mathrm{SO}$ & 32,0 \\
$\mathrm{~B}$ & 1,0 \\
$\mathrm{Cu}$ & 0,06 \\
$\mathrm{Fe}$ & 25,0 \\
$\mathrm{Mn}$ & 1,0 \\
$\mathrm{Mo}$ & 0,03 \\
$\mathrm{Zn}$ & 0,10 \\
\hline \hline
\end{tabular}

A análise do teor de aluminio foi realizada na Seção de Química Analítica do CENA/USP, através de espectrometria de emissão atômica com plasma induzido de argônio, em aparelho Jarrel Ash, modelo 975 .

Os resultados do experimento foram submetidos a análise de variância, sendo as médias comparadas através do teste de Tukey. As análises foram realizadas utilizando-se o pacote estatístico SAS - Statistical Analysis System.

\section{RESULTADOS E DISCUSSĀO}

Efeito do alumínio sobre o crescimento e produçăo de matéria seca: Os efeitos dos tratamentos com alumínio na produção de matéria seca das folhas, caule e raizes, na altura das plantas, no comprimento de raizes e na relação parté aérea/raizes estão expostos na TABELA 2.

Os parâmetros analisados foram afetados pelos tratamentos. Não houve diferença significativa na altura das plantas, mas houve a tendência de maior altura nas doses de até $20 \mathrm{ml} / \mathrm{l}$ de $\mathrm{Al}$ na solução. No comprimento das raizes, não houve diferença significativa na presença do Al, mas na ausência do alumínio o comprimento foi menor. Apesar da altura das plantas nas doses de 20 a $40 \mathrm{mg} / \mathrm{l}$ terem sido maiores que a testemunha, verifica-se que eles diminuíram em relação às doses 5,10 e $15 \mathrm{mg} /$.

Quanto ao peso da matéria seca das folhas, observou-se efeito positivo do Al até a dose de 15 $\mathrm{mg} / \mathrm{l}$, tendo tido a maior produção nesta dose, embora seja semelhante à dose $10 \mathrm{mg} / \mathrm{l}$, diferindo estatísticamente dos demais tratamentos. $\mathrm{O}$ mesmo foi observado para a matéria seca do caule e das raízes, embora, nas raizes, a dose de $15 \mathrm{ml} / \mathrm{l}$ tenha tido efeito semelhante à dose de $5 \mathrm{mg} / \mathrm{l}$, diferindo dos demais tratamentos.

A relação parte aérea/raiz não foi afetada pela adição de Al na solução, mostrando-se, com isso, que o efeito do alumínio foi homogêneo na planta inteira. Segundo HELYAR (1978), as doses crescentes de alumínio causam um declinio exponencial na produção da parte aérea. Quando se usam espécies mais tolerantes, nota-se um estimulo na produção em baixas doses de alumínio, mas o declínio volta a aparecer em altas doses.

Embora o alumínio não seja considerado um elemento essencial, e ainda se desconheçam os mecanismos pelos quais, em baixas concentrações, ele possa, algumas vezes, induzir um aumento no crescimento ou produzir outros efeitos desejáveis, FOY (1974) e MARSCHNER (1986) discutem varias possibilidades de explicacao para o fato: 1) aumento na disponibilidade do ferro em solos calcáreo (através da hidrólise do Al e da diminuição do $\mathrm{pH}$ ); 2) correção ou prevenção de deficiência de ferro, pela liberação do ferro adsorvido em sítios metabolicamente inativos dentro da planta; 3) bloqueia sítios, na parede celular, carregados negativamente, promovendo a absorção de fósforo; 4) retardamento da deterioração das raizes em baixas concentrações de cálcio pelo crescimento mais lento; 5) correção ou prevenção do efeito de concentrações excessivas de fósforo; 6) prevenção de toxidez de cobre e manganês; 7) redução do crescimento indesejável do topo de porta-enxertos ricos em nitrogênio. 
TABELA 2. Efeito de concentraç̃̃es de alumínio na solução nutritiva na altura, comprimento das raizes e peso da matéria seca das folhas, caule e raizes de pimenteira do reino (1).

\begin{tabular}{|c|c|c|c|c|c|c|c|}
\hline \multirow{2}{*}{$\begin{array}{l}\text { Doses de } \\
\mathrm{Al}^{3+}(\mathrm{mg} / \mathrm{l})\end{array}$} & \multirow{2}{*}{$\begin{array}{c}\text { Altura da } \\
\text { planta (cm) }\end{array}$} & \multirow{2}{*}{$\begin{array}{l}\text { Comprimento } \\
\text { raizes }(\mathrm{cm})\end{array}$} & \multicolumn{4}{|c|}{ Peso da matéria seca(g/planta) } & \multirow{2}{*}{$\begin{array}{c}\text { Relação P.A. } \\
\text { raizes }\end{array}$} \\
\hline & & & Folhas & Caule & Raízes & Total & \\
\hline 0 & $115 \mathrm{a}$ & $43 \mathrm{~b}$ & $16,58 \mathrm{~d}$ & $11,15 \mathrm{e}$ & $3,12 \mathrm{~d}$ & $30,85 \mathrm{~d}$ & $8,89 a$ \\
\hline 5 & $138 \mathrm{a}$ & $64 \mathrm{a}$ & $24,52 \mathrm{bc}$ & $20,01 \mathrm{~b}$ & 5,73ab & $50,26 \mathrm{~b}$ & $7,77 \mathrm{a}$ \\
\hline 10 & $141 \mathrm{a}$ & $61 \mathrm{a}$ & $27,69 \mathrm{ab}$ & $18,37 b c$ & $4,69 b c$ & $50,75 b$ & $9,82 a$ \\
\hline 15 & $137 \mathrm{a}$ & $62 \mathrm{a}$ & $30,15 a$ & $29,31 a$ & $6,56 a$ & $66,02 a$ & $9,06 a$ \\
\hline 20 & $139 a$ & $59 \mathrm{ab}$ & $20,75 \mathrm{~cd}$ & $15,04 \mathrm{~cd}$ & $4,34 c$ & $40,13 c$ & $8,25 a$ \\
\hline 40 & $120 \mathrm{a}$ & $71 \mathrm{a}$ & $18,01 d$ & $14,23 \mathrm{de}$ & $3,52 \mathrm{~cd}$ & $35,76 \mathrm{~cd}$ & $9,16 \mathrm{a}$ \\
\hline D.M.S. (5\%) & 37,23 & 17,81 & 4,73 & 3,54 & 1,19 & 7,65 & 2,96 \\
\hline C.V. $(\%)$ & 12,60 & 13,23 & 9,18 & 8,74 & 11,36 & 7,46 & 14,75 \\
\hline
\end{tabular}

(1) Médias seguidas pela mesma letra nas colunas, não apresentam diferença significativa, ao nível de $5 \%$ de probabilidade, pelo teste de Tukey.

TABELA 3. Composição quimica das folhas ( $1^{\circ}$ folha dos ramos frutiferos a $2 / 3$ abaixo da copa) das pimenteiras, amostradas 215 dias após o início dos tratamentos (1).

\begin{tabular}{|c|c|c|c|c|c|c|c|}
\hline Doses de & $\mathrm{P}$ & $\mathbf{K}$ & $\mathrm{Ca}$ & $\mathrm{Mg}$ & Al & Mn & $\mathrm{Fe}$ \\
\hline \multicolumn{2}{|c|}{$\mathrm{Al}^{3+}(\mathrm{mg} / \mathrm{l})$} & \multicolumn{3}{|c|}{ :\% } & \multicolumn{3}{|c|}{ ug/g - } \\
\hline 0 & $0,14 a$ & $1,77 \mathrm{~d}$ & $1,15 a$ & $0,59 a$ & $150 d$ & $176 a$ & 325 \\
\hline 5 & $0,10 \mathrm{ab}$ & $1,90 \mathrm{~cd}$ & $1,07 \mathrm{a}$ & $0,51 \mathrm{a}$ & $208 c$ & $226 a$ & $190 \mathrm{~b}$ \\
\hline 10 & $0,09 \mathrm{ab}$ & $2,29 a$ & $0,87 a$ & $0,48 \mathrm{ab}$ & $222 \mathrm{bc}$ & $210 a$ & $196 \mathrm{~b}$ \\
\hline 15 & $0,09 \mathrm{ab}$ & $1,98 \mathrm{bcd}$ & $0,99 a$ & $0,44 a b$ & $231 \mathrm{bc}$ & $204 a$ & $174 \mathrm{~b}$ \\
\hline 20 & $0,09 \mathrm{ab}$ & $2,18 a b$ & $0,96 a$ & $0,43 \mathrm{ab}$ & $270 \mathrm{ab}$ & $193 a$ & $155 \mathrm{~b}$ \\
\hline 40 & $0,08 b$ & $2,14 a b c$ & $0,68 \mathrm{a}$ & $0,42 \mathrm{ab}$ & $305 a$ & $175 a$ & $221 \mathrm{~b}$ \\
\hline D.M.S. (5\%) & 0,05 & 0,28 & 0,53 & 0,31 & 48 & 82 & 69 \\
\hline C.V. $(\%)$ & 24,68 & 6,07 & 24,60 & 33,02 & 9,26 & 18,46 & 14,61 \\
\hline
\end{tabular}

(1) Médias seguidas pela mesma letra nas colunas, não apresentam diferença significativa, ao nível de $5 \%$ de probabilidade, pelo teste de Tukey.

Efeito do alumínio na composição química da pimenteira do reino: Os dados analíticos referentes aos teores de fósforo, potássio, cálcio, magnésio, alumínio, manganês e ferro nas folhas para diagnóstico, em função das doses de $\mathrm{Al}$, são apresentados na TABELA 3.

Os teores de alumínio aumentaram progressivamente de acordo com os incrementos de sua concentração na solução nutritiva. Em geral, o alumínio adicionado na solução fez decrescer os teores $\mathrm{P}, \mathrm{Ca}, \mathrm{Mg}$, e Fe e aumentou a concentração de $\mathrm{K}, \mathrm{Al}$, e Mn. Os resultados indicaram que a diminuição desses nutrientes pode ser atribuída ao efeito direto de alumínio na absorçăo de $\mathrm{P}, \mathrm{Ca}$ e $\mathrm{Mg}$, concordando com os publicados por FOY (1974).
Com relação à presente discussão, é de interesse a menção dos resultados de ANDREW et al. (1973) que verificaram que o aumento na absorção de potássio pode ter ocorrido devido à capacidade das plantas em preservar um balanço catiônico.

Quanto aos teores de manganês, pode-se observar que aumentaram com elevação das concentrações de alumínio em solução. Entretanto, apesar dos teores obtidos não se observou efeito de toxidez de $\mathrm{Mn}$ nas pimenteiras.

Efeito do aluminio sobre a extraçāo de nutrientes: Fósforo: Nas TABELAS 4, 5 e 6, estão contidas as quantidades de fósforo nas diversas partes das plantas em função das doses de aluminio. Ob- 
serva-se que o aumento da concentração de alumínio na solução aumentou a quantidade de fósforo até a dose de $15 \mathrm{mg} / \mathrm{l}$, decrescendo nas doses 20 e $40 \mathrm{mg} \mathrm{Al} /$, nas folhas, no caule e nas raizes. Isso permite inferir que, em doses superiores a $15 \mathrm{mg}$ $\mathrm{A} / 1$ na solução, esse elemento pode afetar o desenvolvimento de pimenteiras.

De acordo com MARSCHNER (1986), o alumínio pode afetar diretamente a absorção de fósforo através de formação de complexos que se precipitam como fosfato de Al na superficie da raiz, e/ ou. no espaço livre aparente (ELA).

Potássio: Nas TABELAS 4, 5 e 6, são apresentados os conteúdos de potássio nas diversas partes da planta. Verifica-se que houve um aumento no acúmulo de potássio com a adição de até $15 \mathrm{mg}$ $\mathrm{Al} / \mathrm{I}$ na solução nutritiva, apesar de se observar uma tendência decrescente a partir de $20 \mathrm{mg} \mathrm{Al} / \mathrm{l}$, nas folhas, no caule e nas raizes. $O$ fato sugere que $O$ efeito principal do alumínio sobre a acumulação de potássio ocorre, provavelmente, através da redução do tamanho radicular e da capacidade de absorção.

Aspecto interessante a ser mencionado, o estímulo no crescimento e na absorção de nutrientes, pelo alumínio, em baixas concentrações, já foram observados para Eucalyptus por MULLETTE (1975), e para outras espécies vegetais por vários autores (ANDREW et al., 1973).

Cálcio: Nas TABELAS 4, 5 e 6, estão expressas as quantidades de cálcio contidas nas diversas partes da planta. Verifica-se um aumento nas quantidades contidas nas folhas, caule e raizes, com a adição da dose de $\mathrm{Al}$ na solução até $15 \mathrm{mg} / \mathrm{l}$, dose em que se obtiveram os maiores valores, com diminuição nas quantidades, a partir das doses 20 e 40 $\mathrm{mg} \mathrm{Al} / \mathrm{l}$. Os dados indicam que, na dose mais alta (40 $\mathrm{mg} \mathrm{Al} / \mathrm{l}$ ), apareceram as menores quantidades de cálcio.
Do mesmo modo, FOY (1984), verificou que a toxidez de $\mathrm{Al}$ pode se manifestar como uma deficiência de $\mathrm{Ca}$ induzida, em consequência de uma redução do transporte do nutriente na planta, provocando um colapso nos pontos de crescimento em valores de $\mathrm{pH}<5,5$. $\mathrm{O}$ antagonismo $\mathrm{Al} \times \mathrm{Ca}$ talvez seja o fator mais limitante na absorção de $\mathrm{Ca}$.

Magnésio: As quantidades de magnésio encontradas nas folhas, caule e raizes, em função das doses de alumínio, estão contidas nas TABELAS 4, 5 e 6 . Observa-se que a presença de aluminio na solução nutritiva promoveu um pequeno estímulo na absorção de magnésio, pois as maiores quantidades de magnésio nas folhas e no caule ocorreram na dose $15 \mathrm{mg} \mathrm{Al} / \mathrm{l}$, enquanto, na raiz, verificou-se o mesmo efeito com a dose $10 \mathrm{mg} \mathrm{Al} / \mathrm{l}$, estatísticamente semelhante à dose $15 \mathrm{mg} \mathrm{Al} / \mathrm{l}$. As plantas submetidas às doses mais elevadas, 20 e $40 \mathrm{mg} \mathrm{Al} / \mathrm{l}$, mostraram uma tendência de redução nas quantidades de $\mathrm{Mg}$ nas folhas, caule e raizes.

Alumínio: As quantidades de aluminio encontradas nas diversas partes das plantas, em funçăo dos tratamentos estão apresentadas nas TABELAS 4, 5 e 6 . Verifica-se que as quantidades de alumínio acumuladas pelas plantas, alcançaram valores elevados nas folhas, caule e raizes, principalmente na dose de $15 \mathrm{mg} / \mathrm{l}$, ocorrendo decréscimo nas doses 20 e $40 \mathrm{mg} \mathrm{Al} / \mathrm{l}$. Observou-se também que, mesmo na ausência de $\mathrm{Al}$, houve uma considerável quantidade desse elemento nas plantas. Uma explicagão para esse fato é que, usualmente, plantas superiores contêm cerca de 200 ppm de Al na matéria seca (MENGEL \& KIRKBY, 1987). Os resultados do presente experimento indicaram que as raizes foram o principal órgão afetado por quantidades excessivas de alumínio na solução nutritiva.

Segundo FOY (1984), o excesso de Al nas plantas ern geral interfere na divisão celular das

TABELA 4. Quantidades médias de nutrientes e aluminio, existentes nas folhas das pimenteiras do reino, submetidas à doses de aluminio na solução nutritiva (1)

\begin{tabular}{|c|c|c|c|c|c|c|c|}
\hline $\begin{array}{c}\text { Doses de } \mathrm{Al}^{3+} \\
(\mathrm{mg} / \mathrm{l})\end{array}$ & $\mathrm{P}$ & $\mathrm{K}$ & $\begin{array}{c}\mathrm{Ca} \\
\text { lanta }\end{array}$ & $\mathrm{Mg}$ & Al & $\begin{array}{c}\text { Mn } \\
\text { ug/planta }\end{array}$ & $\mathrm{Fe}$ \\
\hline 0 & $21,92 \mathrm{bcd}$ & $304,54 c$ & $197,91 \mathrm{~cd}$ & $79,99 c$ & $3565,2 b$ & $7097,8 \mathrm{~cd}$ & $4467,9 \mathrm{c}$ \\
\hline 5 & $24,44 \mathrm{abc}$ & $598,56 a$ & $296,29 \mathrm{ab}$ & $138,79 \mathrm{ab}$ & $6659,9 a$ & $8780,9 b c$ & $7520,7 b$ \\
\hline 10 & $29,39 \mathrm{ab}$ & $603,63 \mathrm{a}$ & $273,18 \mathrm{abc}$ & c $151,41 \mathrm{a}$ & $5917,0 \mathrm{a}$ & $8899,0 b$ & $8104,8 b$ \\
\hline 15 & $30,76 \mathrm{ab}$ & $621,58 \mathbf{a}$ & $337,13 \mathbf{a}$ & $164,63 a$ & $5675,6 a$ & $12679,5 a$ & $10333,5 \mathrm{a}$ \\
\hline 20 & $20,29 \mathrm{~cd}$ & $469,25 b$ & $241,54 b c$ & $118,40 b$ & $3925,3 b$ & $6915,8 d$ & $8256,5 b$ \\
\hline 40 & $16,63 d$ & $268,76 c$ & $124,51 d$ & $80,93 c$ & $2394,7 \mathrm{c}$ & $4958,6 \mathrm{e}$ & $4480,3 c$ \\
\hline DMS. $(5 \%)$ & 7,75 & 97,67 & 77,30 & 32,20 & 1010,70 & 1793,10 & 1488,80 \\
\hline C.V. $(\%)$ & 14,42 & 9,10 & 14,03 & 11,71 & 9,59 & 9,71 & 9,21 \\
\hline
\end{tabular}

(1) Médias seguidas pela mesma letra nas colunas, não apresentam diferença significativa, ao nível de $5 \%$ de probabilidade, pelo teste de Tukey. 
raizes, aumenta a rigidez da parede celular pela ligação com as pectinas, reduz a produção de ácido desoxiribonucleico (DNA), diminui a respiração das raizes, interfere na ação das enzimas que governam a fosforilação de acúcares e precipita polissacarídeos da parede celular, além de perturbar a absorção, transporte e uso de vários nutrientes como fósforo, potássio, cálcio, magnésio e ferro.

MARSCHNER (1986) relats que a acumulação de alumínio ocorre especialmente no núcleo das células das raízes, e que, nesse caso, o efeito pode ser resultado da injúria a esse orgăo.

De acordo com FOY et al. (1978), vários fenômenos ajudam a explicar a tolerância ao alumínio verificada entre e dentro de espécies: 1) algumas espécies (arroz, milho) que aumentam o pH do meio e, assim, diminuem a solubilidade e a toxidez do alumínio, são tolerantes; já as que não modificam o pH do substrato são sensíveis; 2) a tolerância pode estar relacionada a um mecanismo de absorção que exclui o excesso de Al do processo. Outras plantas podem transportar menos alumínio para a parte aérea, concentrando este elemento nas raízes; 3 ) em cultivares de trigo, cevada e soja, a tolerância ao Al está associada à capacidade de absorver mais cálcio ou de transportá-lo para a parte aérea; 4) de um modo geral, a tolerância ao alumínio, em muitas espécies, se relaciona positivamente à capacidade de absorver e utilizar fósforo.

Um outro aspecto de interesse, em relação à tolerância interna, é a verificação de que muitas espécies tolerantes parecem responder favoravelmente a adições moderadas de alumínio na solução (FOY, 1974).

TABELA 5. Quantidades médias de nutrientes e alumínio, existentes no caule das pimenteiras do reino, submetidas à doses de alumínio na solução nutritiva (1).

\begin{tabular}{|c|c|c|c|c|c|c|c|}
\hline Doses de & $\mathbf{P}$ & K & $\mathrm{Ca}$ & $\mathbf{M g}$ & Al & Mn & $\mathrm{Fe}$ \\
\hline 0 & $11,08 b$ & $249,52 c$ & $74,53 \mathrm{c}$ & $27,36 \mathrm{~cd}$ & $771,6 \mathrm{c}$ & $3233,9 b$ & $950,8 \mathrm{c}$ \\
\hline 5 & $11,48 \mathrm{~b}$ & $315,15 b c$ & $106,15 b$ & $49,94 \mathrm{ab}$ & $1361,4 b$ & $4473,4 \mathrm{a}$ & $2325,2 \mathrm{~b}$ \\
\hline 10 & $14.42 \mathrm{ab}$ & $333,36 b$ & $88,17 b c$ & $39,33 b c$ & $1318,7 b$ & $2491,1 \mathrm{c}$ & $2281,3 b$ \\
\hline 15 & $16,86 \mathrm{a}$ & $457,88 \mathrm{a}$ & $147,15 a$ & $62,71 \mathrm{a}$ & $1811,8 \mathfrak{a}$ & $4267,7 \mathrm{a}$ & $4696,2 a$ \\
\hline 20 & $11,09 \mathrm{~b}$ & $307,80 \mathrm{bc}$ & $71,62 \mathrm{c}$ & $29,92 \mathrm{~cd}$ & $902,0 \mathrm{c}$ & $2517,4 \mathrm{c}$ & $2233,1 \mathrm{~b}$ \\
\hline 40 & $12,04 \mathrm{~b}$ & $338,36 \mathrm{~b}$ & $60,82 \mathrm{c}$ & $23,02 d$ & $767,5 \mathrm{c}$ & $3468,8 b$ & $2178,1 b$ \\
\hline D.M.S.(5\%) & 4,81 & 66,19 & 31,29 & 14,00 & 331,65 & 692,33 & 490,64 \\
\hline C.V. (\%) & 16,70 & 8,84 & 15,23 & 16,10 & 12,77 & 9,04 & 8,93 \\
\hline
\end{tabular}

(1) Médias seguidas pela mesma letra nas colunas, não apresentam diferença significativa, ao nível de $5 \%$ de probabilidade, pelo teste de Tukey.

TABELA 6. Quantidades médias de nutrientes e alumínio, existentes nas raízes das pimenteiras do reino, submetidas à doses de alumínio na solução nutritiva (1).

\begin{tabular}{|c|c|c|c|c|c|c|c|}
\hline Doses de & $\mathbf{P}$ & $\mathbf{K}$ & $\mathrm{Ca}$ & $\mathbf{M g}$ & Al & $\mathrm{Mn}$ & $\mathbf{F e}$ \\
\hline 0 & $6,24 c$ & $56,73 \mathrm{c}$ & $9,46 \mathrm{c}$ & $4,55 b$ & $284,80 \mathrm{c}$ & $3685 \mathrm{c}$ & $1149 c$ \\
\hline 5 & $7,99 \mathrm{bc}$ & $88,27 a b$ & $20,35 a$ & $11,39 \mathrm{a}$ & $605,29 b$ & $27712 b$ & $12243 b$ \\
\hline 10 & $8,41 a b$ & $73,22 \mathrm{bc}$ & $14,70 \mathrm{abc}$ & $14,22 \mathrm{a}$ & $627,29 \mathrm{~b}$ & $28645 b$ & $11074 b$ \\
\hline 15 & $10,14 a$ & $105,40 \mathrm{a}$ & $19,13 a b$ & $14,09 a$ & $829,27 a$ & $40275 a$ & $15484 a$ \\
\hline 20 & $6,75 \mathrm{bc}$ & $65,00 \mathrm{c}$ & $13,74 \mathrm{bc}$ & $12,45 a$ & $557,95 \mathrm{~b}$ & $22529 b$ & $12125 b$ \\
\hline 40 & $5,87 \mathrm{c}$ & $72,04 b c$ & $8,76 \mathrm{c}$ & $4,81 b$ & $373,53 \mathrm{c}$ & $23099 b$ & $11041 b$ \\
\hline D.M.S.(5\%) & 2,14 & 19,55 & 6,21 & 4,10 & 135,01 & 74112 & 2846 \\
\hline C.V.(\%) & 12,57 & 11,33 & 19,26 & 17,82 & 10,99 & 13,56 & 12,04 \\
\hline
\end{tabular}

(1) Médias seguidas pela mesma letra nas colunas, não apresentam diferença significativa, ao nível de $5 \%$ de probabilidade, pelo teste de Tukey. 
Manganês: As quantidades de manganês encontradas nas diferentes partes das plantas, em função das doses de alumínio, estão contidas nas TABELAS 4, 5 e 6. Nota-se que houve aumento nas quantidades de manganês nas folhas, caule e raízes, com a adição de aluminio na solução até a dose de $15 \mathrm{mg} / \mathrm{l}$, decrescendo nas doses superiores. Entretanto, os teores obtidos não tem se mostrado tóxicos para plantas de pimenta do reino, de acordo com as observações.

Por outro lado, MENGEL \& KIRKBY (1987) observaram que, frequentemente, altos niveis de manganês nos tecidos das plantas estão associados à toxidez de alumínio. Entretanto ALAM (1983) verificou que, no arroz, o aumento de $\mathrm{Al}$ na solução promoveu uma diminuição do teor de Mn na parte aérea, enquanto, nas raizes, ocorreram aumentos, sugerindo que o manganês pode competir efetivamente com o Al pelos sítios ativos de absorção.

Ferro Nas TABELAS 4, 5 e 6, estão expressos os valores das quantidades de ferro para as diversas partes das plantas, em função dos tratamentos com aluminı Observou-se que a menor quantidade de ferro ocorreu na ausência de $\mathrm{Al}$ no caule e nas raizes, enquanto, nas folhas, foi constatada na presença de $40 \mathrm{mg} \mathrm{Al} / \mathrm{l}$. À medida que se aumentou a dose de alumínio na solução, a quantidade de ferro se elevou Contudo as maiores quantidades de ferro ocorrerram na dose de $15 \mathrm{mg} \mathrm{Al} /$, para folhas e raizes, e na dose de $5 \mathrm{mg} \mathrm{Al} / \mathrm{l}$ para caule. Esses resultados estão de acordo com as observações de MENGEL \& KIRKBY (1987), que relataram que a toxidez de Al está sempre acompanhada por altos niveis de ferro. Em arroz, ALAM (1983) observou um maior acúmulo de ferro nas raízes, com aumento, da concentração de Al, superior a $10 \mathrm{ppm}$.

Efeito de alumínio na distribuição de nutrientes nas razes e parte aérea: A TABELA 7, mostra a influência do $\mathrm{Al}$ na distribuição de alguns nutrientes nas raizes e parte aérea.

A percentagem de $\mathrm{K}, \mathrm{Ca}, \mathrm{Mg}$ e $\mathrm{Mn}$, na parte aérea, foi maior do que nas raizes, não havendo diferença de distribuição em função dos tratamentos com alumínio. Para o fósforo, percebeu-se distribuição equitativa para a parte aérea e raízes, não se notando influência das doses de alumínio. Por outro lado, a percentagem de ferro e alumínio nas raizes aumentou enquanto a que permaneceu na parte aérea das plantas diminuiu, com os tratamentos de Al. Usualmente quando há toxidez de alumínio verifica-se maior proporção de fósforo nas raizes, o que não aconteceu neste caso.

Sintomas de toxidez de alumínio: $O$ primeiro sintoma visual da toxidez de alumínio na pimenteira foi a redução do sistema radicular.

O crescimento da região apical foi ınıbido, $\mathrm{e}$ as raizes submetidas ao alumínio apresentavam-se grossas, com aspecto quebradiço, além de uma coloração amarelo-escura ou marron, provavelmente como resultado da inibição das raizes. Todo o sistema radicular apresentou-se enegrecido e com aspecto coralóide, sem ramificações das laterais $\mathrm{Na}$ parte aérea das plantas, os sintomas não mostraram semelhança com os de deficiência de fósforo e pota sio (MALAVOLTA \& KLIEMANN, 1985). As fothas velhas apresentavam uma coloração verde- escura a purrpura, com pequeno amarelecimento a partir das margens, seguido de queda precoce das mesmas. Os sinais de toxidez ficaram mais evidentes nos tratamentos com 15,20 e $40 \mathrm{mg} \mathrm{Al} / /$.

Alguns aspectos observados em pimenteira neste experimento são semelhantes às descrições apresentadas por MENGEL \& KIRKBY (1987), PAVAN \& BINGHAM (1982), em cafeeiros, e por FOY (1984), para outras espécies afetadas pela toxidez de aluminio.

TABELA 7. Influências das concentrações de $\mathrm{Al}$ em solução nutritiva na distribuição de nutrientes e $\mathrm{Al}$ nas raizes e parte aérea das pimenteiras, 215 dias após o início dos tratamentos.

\begin{tabular}{|c|c|c|c|c|c|c|c|c|c|c|c|c|c|c|}
\hline \multirow{3}{*}{$\begin{array}{l}\text { Doses de } \\
\mathrm{Al}^{3+}(\mathrm{mg} / \mathrm{l})\end{array}$} & \multicolumn{14}{|c|}{ Distribuição de nutrientes (\%) } \\
\hline & \multicolumn{2}{|c|}{$\mathbf{P}$} & \multicolumn{2}{|c|}{ K } & \multicolumn{2}{|c|}{$\mathrm{Ca}$} & \multicolumn{2}{|c|}{$\mathrm{Mg}$} & \multicolumn{2}{|c|}{$\mathrm{Mn}$} & \multicolumn{2}{|c|}{$\mathrm{Fe}$} & \multicolumn{2}{|l|}{$\mathrm{Al}$} \\
\hline & PA* & Raiz & $\mathrm{PA}^{*}$ & Raiz & $\mathrm{PA}^{*}$ & Raiz & $\mathrm{PA}^{*}$ & Raiz & $\mathrm{PA}^{*}$ & Raiz & PA* & Raiz & $\mathrm{PA}^{*}$ & Raiz \\
\hline 0 & 54 & 46 & 69 & 31 & 86 & 14 & 83 & 17 & 76 & 24 & 38 & 62 & 49 & 51 \\
\hline 5 & 53 & 47 & 72 & 28 & 83 & 17 & 80 & 20 & 76 & 24 & 11 & 89 & 17 & 83 \\
\hline 10 & 51 & 49 & 72 & 28 & 82 & 18 & 72 & 28 & 68 & 32 & 7 & 93 & 15 & 85 \\
\hline 15 & 51 & 49 & 69 & 31 & 85 & 15 & 78 & 22 & 66 & 34 & 8 & 92 & 17 & 83 \\
\hline 20 & 53 & 47 & 74 & 26 & 84 & 16 & 73 & 27 & 66 & 34 & 9 & 91 & 16 & 84 \\
\hline 40 & 51 & 49 & 65 & 35 & 82 & 18 & 82 & 18 & 64 & 36 & 7 & 93 & 11 & 89 \\
\hline
\end{tabular}

P.A.* = parte aérea 


\section{CONCLUSŌES}

Os resultados obtidos neste trabalho, permitiram as seguintes conclusões:

Observou-se efeito positivo do alumínio na produção de matéria seca das folhas, caule e raizes até a dose de $15 \mathrm{mg} \mathrm{Al} / \mathrm{l}$, tendo tido a maior produção nesta dose, o que correspondeu a uma maior absorção de $\mathrm{P}, \mathrm{K}, \mathrm{Ca}, \mathrm{Mg}, \mathrm{Mn}, \mathrm{Fe}$ e Al.

$A$ adição de $20 \mathrm{mg} \mathrm{Al} / /$ diminuiu o peso da matéria seca e a absorção de nutrientes e $\mathrm{Al}$, o qual foi associado com o início do efeito da toxidez. O sintoma inicial de toxidez de alumínio foi caracterizado por um retardamento no crescimento radicular, com aumento no diâmetro das raizes.

A pimenteira do reino é acumuladora e tolerante à presença de concentrações de alumínio inferiores a $20 \mathrm{mg} / 1$ no substrato. Doses superiores provocam distúrbios nutricionais na planta.

\section{REFERÊNCIAS BIBLIOGRÁFICAS}

ALAM, S.M. Effect of aluminum on the dry matter and mineral content of rice. Journal of Science Technology, Peshawar, v.7, n. 1/2, p.1-3, 1983.

ALBUQUERQUE, F.C. de; VELOSO, C.A.C.; DUARTE, M.L.R.; KATO, O.R. Pimenta do reino: recomendações básicas para seu cultivo. Belém, EMBRAPA-UEPAE de Belém, 1989. 40p. (EMBRAPA-UEPAE de Belém. Documentos, 12).

ANDREW, C.S.; JOHNSON, A.D.; SANDLAND, R.L. Effect of aluminum on the growth and chemical composition of some tropical and temperate pasture legumes. Australian Journal of Agricultural Research, Victória, v.24, p.325-339, 1973.

CAMBRAIA, J. Mecanismos de tolerância a toxidez de alumínio em plantas. In: REUNIÃO BRASILEIRA DE FISIOLOGIA VEGETAL, 2., Piracicaba, 1989. Anais... Piracicaba: SBFV; ESALQ, 1989. p.85-92.

FALESI, I.C. O estado atual dos conhecimentos sobre os solos da Amazônia Brasileira. In:INSTITUTO DE PESQUISA E EXPERIMENTAÇÃO AGROPECUÁRIA DO NORTE. Zoneamento agrícola da Amazônia. Belém: IPEAN, 1972. p.17-67. (IPEAN. Boletim Técnico, 54).

FOY, C.D. Effect of aluminum on plant growth. In: CARSON, F.W., (Ed.) The plant root and its environment. Charlottesville: University Press of Virginia, 1974. p.601642.

FOY, C.D. Physiological effects of hydrogen, aluminum and manganese toxicities in acid soil. In: ADAMS, F., ed. Soil acidity and liming. 2.ed. Madison, Soil Science Society of America, 1984. p.57-97.

Sci. agric., Piracicaba, 52 (2): 368 -375, mai./ago. 1995
FOY, C.D. Soil chemical factors limiting plant root growth. In: HATFIELD, J.L.; STEWART, B.A. Limitations to plant mot growth. New York: Springer-Verlag, 1992. p.97-149.

FOY, C.D.; CHANEY, R.L.; WHITE, M.C. The physiology of metal toxicity in plants. Annual Review of Plant Physiology, Lancaster, v.29, p.511-566, 1978.

FURLANI, P.R. Efeitos fisiológicos do aluminio em plantas. In: SIMPÓSIO AVANÇADO DE SOLOS E NUTRIÇÃO DE PLANTAS, 2., Piracicaba, 1989. Anais. Campinas, Fundação Cargill, 1989. p.73-90.

HELYAR, K.R. Effects of aluminum and manganese toxicity on legume growth. In: ANDREW, C.S.; KAMPRATH, E.J. (Ed.) Mineral nutrition of legumes in tropical and subtropical soils. Melbourne: CSIRO, 1978. p.207-231.

LOPES, A.S. Solos sob "cerrado": características, propriedades e manejo. Piracicaba: Associação Brasileira para Pesquisa da Potassa e do Fosfato, 1984. 162p.

MAISTRE, J. Las pimientas. In: Las plantas de especias. Barcelona: Ed. Blume, 1969. p.123-208.

Malavolta, E.; KLIEMANN, H.J. Desordens nutricionais no cerrado. Piracicaba: Associação Brasileira para Pesquisa da Potassa e do Fosfato, 1985. 136p.

MALAVOLTA, E.; VITTI, G.C.; OLIVEIRA, S.A. de. Avaliação do estado nutricional das plantas; principios e aplicações. Piracicaba: Associação Brasileira para Pesquisa da Potassa e do Fosfato, 1989. 201p.

MARSCHNER, $H$. Mineral nutrition of higher plants. London: Academic Press, 1986. 674p.

MENGEL, K.; KIRKBY, E.A. Principles of plant nutrition. 4.ed. Worblaufen-Bern: International Potash Institute, 1987. 687p.

MULLETTE, K.J. Stimulation of growth in Eucalyptus due to aluminum. Plant and Soll, The Hague, v.42, p.495$499,1975$.

PAVAN, M.A; BINGHAM, F.T. Toxidez de alumínio em cafeeiros cultivados em solução nutritiva. Pesquisa Agropecuária Brasileira, Brasilia, v.17, n.9, p.1293$1302,1982$.

PRATT, P.F. Aluminum. In: CHAPMAN, H.D. (Ed.) Diagnostic criteria for plants and soils. Berkeley: University of California, Division of Agricultural Science, 1966. p.3-12.

WAARD, P.W.F. de. Foliar diagnosis, nutrition and yield stability of black pepper (Piper nigrum, L.) in Sarawak. Amsterdam: Royal Tropical Institute, 1969. 149p. (Communication, 58).

$\overline{\text { Recebido para publicação em } 2} 1.10 .94$

Aceito para publicação em 27.06.95 